\title{
Factors Affecting the Severity of Eye Injuries
}

ISSN: 2577-1914

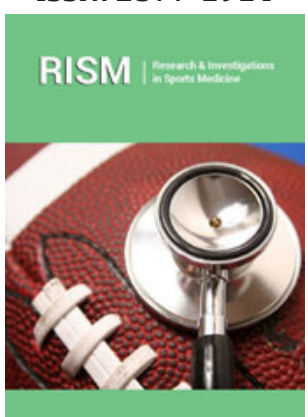

*Corresponding author: Shukla B, RJN Ophthalmic Institute, Gwalior, India

Submission: 䤈 November 13, 2019

Published: 眥December 04, 2019

Volume 5 - Issue 5

How to cite this article: Shukla B Factors Affecting the Severity of Eye Injuries. Res Inves Sports Med. 5(5). RISM.000623.2019.

DOI: $10.31031 /$ RISM.2019.05.000623

Copyright@ Shukla B, This article is distributed under the terms of the Creative Commons Attribution 4.0 International License, which permits unrestricted use and redistribution provided that the original author and source are credited.

\author{
Shukla B* \\ RJN Ophthalmic Institute, India
}

\section{Short Communication}

There are numerous ways of sustaining injuries in human eye. The severity of injury basically depends on the object (injuring agent) and the subject (human eye). These are the basic factors. However, the result would depend on the timing and efficiency of treatment.

\section{The Objective Factor}

This includes a very large number of objects. Some of the factors which carry a poor prognosis could be classified in the given way. The reverse of these factors would indicate a good prognosis.

A. Weight of the object: Anything heavier will obviously cause greater damage even having smaller size and shape. A heavier object may cause more damage even if strikes gently whereas a light object like table tennis ball may not cause much even if strikes with force.

B. Velocity of object: Damage depends on the energy of impact and energy $=1 / 2$ $m . v^{2}$ where ' $m$ ' stands for mass and ' $v$ ' for velocity. Thus, both the factors are almost equally important in causing damage. To some extent the velocity also depends on the distance of object from the eyeball. If the object is close damage is likely to be higher.

C. Direction of object: If the impact occurs directly in forward direction damage would be more as the damage would be transferred to the posterior pole of the eyeball where the most important part of vision (macula and fovea) are situated.

D. Physical nature of object: If the surface of the object is smooth less damage is likely to occur. However, it is rough or pointed at the striking end the damage could be considerable.

E. Chemical nature of object: Damage due to acid and alkali is very great even in a short time and may lead to gross disfigurement.

F. Number of objects: In explosions and blast injuries several small particles may enter in both eyes causing great inconvenience.

\section{The Subjective Factors}

These factors pertain to the eyeball which sustains injury and are no less important than the objective factors. They include:

A. Size of eyeball: At the time of birth the eyeball is fairly small, and it reaches the adult size at about 15 years of age. Not only the size but consistency is also very delicate. Hence the injury to a child with similar object as in an adult would be much greater.

More important than structural status the functional stratus is very unstable. If the vision is only slightly affected in one eye it may lead to squint or amblyopia which are not easy to treat. Even after structural repair functional repair may be very small. Even a slight structural defect in a child may be of great psychological importance in a child during his schooling period. The child does understand the impact of injury and so any type of treatment would be resisted by the child and affect prognosis. Sometimes the child may behave normally because of his ignorance of the condition but the child's injury may be a cause of great. psychological trauma to the parents. 


\section{The Management Factors}

Early effective treatment along with a regular follow up is the key to a good prognosis in these cases. Besides in Western countries, in big cities of Asian countries also the management of eye injuries is quite efficient. However, in rural areas it is far from satisfactory. Even the basic medical treatment is not satisfactory. Thus, in many cases of eye injuries there is considerable delay in treatment. In some cases, complicated surgery is needed which may be quite expensive and parents are not able to afford. Apart from serious attention from governments and medical fraternity a good publicity for early treatment is very necessary which may save many eyes from going to blindness or semi-blindness. Doctors should also get some special training in handling eye injury cases particularly in children. Saving vision of one child is equal to saving vision in five adults. 